\title{
Proksimal tibia medial açık kama osteotomisinde plak fiksatör ile tespit
}

\section{Fixation of medial open-wedge proximal tibial osteotomy using a plate fixator}

\author{
Olcay Güler
}

Altınbaş Üniversitesi Tıp Fakültesi, Ortopedi ve Travmatoloji Anabilim Dalı, Bahçelievler Medicalpark Hastanesi, İstanbul

Proksimal tibia medial açık kama osteotomisi erken evre diz medial kompartman osteoartrit cerrahi tedavisinde, başarılı sonuçlar elde edilen seçeneklerden biridir. Proksimal tibia medial açık kama osteotomi fiksasyonunda plak fiksatör (Tomofiks) sistemi yaygın olarak kullanılmaktadır. Plak fiksatör (Tomofiks) sistemi kilitli kompresyon plak-vida sistemi olarak tasarlanmıştır. Bu sayede biyomekanik olarak osteotomi alanında stabilite artışı elde edilmektedir. Proksimal tibia medial açık kama osteotomi fiksasyonunda plak fiksatör kullanıldığında osteotomi alanında kaynama ve kazanılan düzeltmenin korunması yüksek oranda sağlanmaktadır. Ayrıca düşük açılardaki düzeltmelerde osteotomi hattına greft uygulama gereksinimi azaltmaktadır. Ancak plak fiksatör sisteminin, uzun boyutları ve kalınlığı nedeniyle implant rahatsızlığına neden olarak çıkarılma ihtiyacı olabilmektedir.

Anahtar sözcükler: medial açık kama osteotomisi; plak fiksatör; Tomofiks; fiksasyon

\begin{abstract}
Medial open-wedge proximal tibial osteotomy is among the surgical treatments revealed successful clinical outcomes in patients with early-stage medial compartmental gonarthrosis. Plate fixator system (Tomofix) is commonly used for the fixation of medial open-wedge proximal tibial osteotomy. Plate fixator system (Tomofix) has been designed as a locking compression plate-screw system in order to provide increased biomechanical stability at the site of osteotomy. When plate fixator (Tomofix) used, union at the osteotomy site as well as protecting the acquired correction can be achieved with high success rates. Besides, in low-degree corrections, it reduces necessity of grafting the osteotomy line. On the other hand, dimensions and thickness of the plate fixator may cause need for implant removal due to irritation.
\end{abstract}

Key words: medial open wedge osteotomy; plate fixator; Tomofix; fixation
$\mathbf{P}$ roksimal tibia medial açık kama osteotomisi (PTMAKO), varus deformitesinin eşlik ettiği diz eklemi medial kompartman osteoartrit tedavisinde oldukça yaygın kullanılmaktadır. ${ }^{[1]}$ Osteotomi, varus deformitesi olan dizlerde medial tibiofemoral kompartmana gelen yükleri azaltmaktadır. Mekanik aksın (eksenin) düzeltilmesi sonrası medial eklem yüklenme stresi azalarak hem ağrıyı gidermekte hem de kıkırdak dejenerasyon sürecini yavaşlatabilmektedir. ${ }^{[2]}$ PTMAKO'nin proksimal tibia lateral kapalı kama osteotomisine göre, fibula osteotomisi gerektirmemesi, peroneal sinir yaralanma riskinin düşük olması, kolay uygulanabilmesi ve kemik stok korunması gibi avantajları mevcuttur. Ancak bacak boy uzaması, lateral korteks kırılması, düzeltme kaybı olabilmesi ve greft gerektirebilmesi gibi dezavantajları mevcuttur. ${ }^{[1]}$
Osteotomide ideal tespit yönteminin, yeterli stabilite sağlaması, elde edilen düzeltmeyi koruması ve osteotomi hattının iyileşmesini sağlaması istenmektedir. ${ }^{[3,4]}$ PTMAKO'nde ideal tespit yöntemi mevcut olmasa da günümüzde plaklar (kamalı, metal bloklu, internal plak fiksatör), eksternal fiksatörler ve $U$ çiviler kullanılmaktadır. İlk yıllarda medial açık kama osteotomi hattının fiksasyonu için Goutallier ve ark., destek plağı kullanmışlardır. ${ }^{[5]} 1990$ 'lı yılların başlarında Puddu tarafindan tasarlanan düzeltme kaybını önlemek için osteotomi hattını destekleyen metal blokları olan plaklar kullanılmıştır (Puddu plağı, Arthrex spacer plağı, Arthrex Inc, Naples, FL, USA ). ${ }^{[6]}$ Sonraki yıllarda ön-arka dikey kamalı plaklar (dikey kamalı blok sistem, Aesculap; B. Braun Korea, Seoul, South Korea), ayarlanabilir dereceli yatay kamalı plak (Anthony- K, Clamart, France) ve yatay kamalı

- İletişim adresi: Doç. Dr. Olcay Güler, Altınbaş Üniversitesi Bahçelievler Medicalpark Hastanesi, Kültür Sok. No:1, 34160 Bahçelievler, İstanbul Tel: 0532 - 7047069 e-posta: olcayguler77@gmail.com

- Geliștarihi: 20 Ocak $2020 \quad$ Kabul tarihi: 21 Șubat 2020 


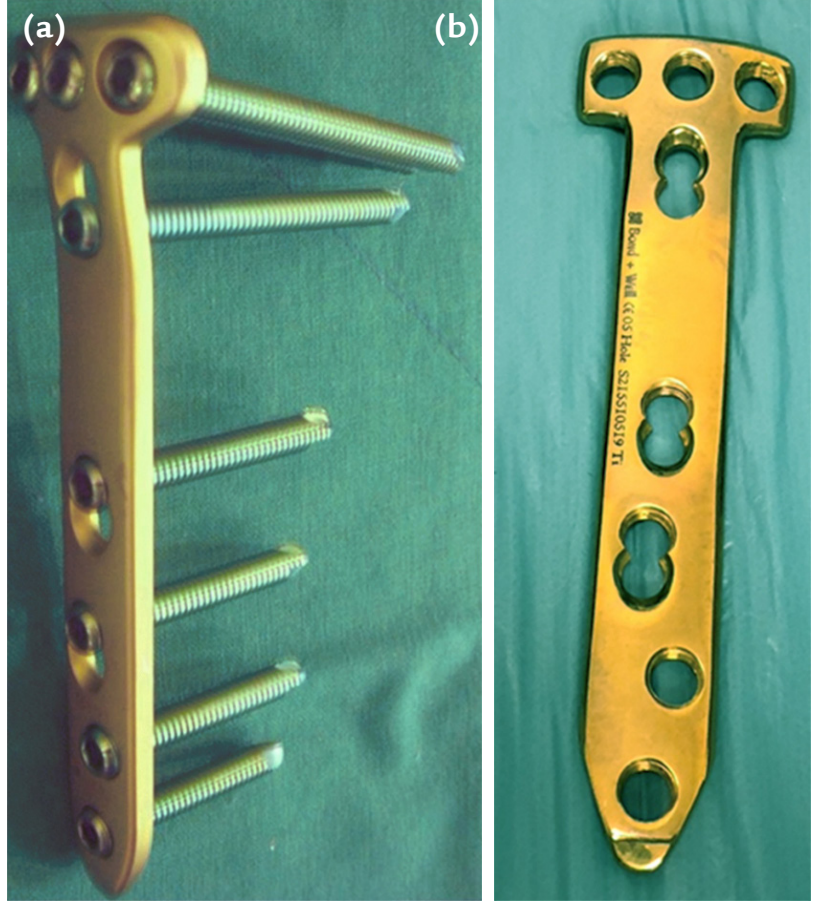

Şekil 1. a, b. Plak fiksatör (Tomofiks) sistemi.

çift plak [(HIPOKRAT) (TIPSAN)]'lar kullanılmıştır. $^{[4,7,8]}$ Kilitli plak teknolojisinin gelişmesine paralel olarak sabit planda kilitli (OrthoFix; Othomedical Co. Ltd., Goyang, Korea) veya çok planlı kilitli (DWLÒ, Tradimedics, Korea) proksimal tibia plakları kullanıma girmiştir. Lobenhoffer ve ark. tarafından tanınır hale getirilen TomoFiks plağı (internal plak fiksatör, plak fiksatör, rijit plak tespiti, Tomofix Osteotomy System; DePuy Synthes, West Chester, PA, USA) ise rijit fiksasyon sağlaması nedeniyle son yıllarda yaygın olarak kullanılmaktadır. ${ }^{[9-11]}$ Plak-fiksatör (Tomofix), kilitli kompresyon plak olarak tasarlanmış ve proksimalde kilitli 5,0 mm'lik dört vida deliği mevcuttur. Distal ise kilitli ve kilitsiz 4,5 mm'lik kortikal vida delikleri mevcuttur (Şekil 1). íki farklı boyda (102 mm ve 141 $\mathrm{mm}$ ) üretilmiştir. PTMAKO'nde fiksasyonda kullanılan plak tipleri arasında fark olmadığını bildiren çalışmalar var olmakla birlikte, kilitli plak tespitinin biyomekanik üstünlüğünü gösteren çalışmalar da mevcuttur. ${ }^{[12]}$ Han ve ark., biyomekanik çalışmasında metal kama içeren kilitli plakların, kama içermeyen kilitli plak ve kısa plaklara daha üstün olduğu bulmuşlardır. ${ }^{[13]}$ Agneskirchner ve ark., dört farklı implantın karşılaştırıldığı çalışmada uzun, rijid ve kilitli vidaları olan fiksatör plakların (Tomofiks), kısa plak vida sistemlerine göre daha stabil olduğu bildirilmişlerdir. ${ }^{[3]}$ Ancak uzun plakların daha kaba ve çok yer kaplaması nedeniyle çıkarılma ihtiyacı olabilmektedir. Takeuchi ve ark.'nın biyomekanik çalışmalarında PTMAKO'sinde plak fiksatörün tibianin proksimal posteromedialine yerleştirmenin en güçlü stabiliteyi sağladığını belirtmişlerdir. ${ }^{[14]}$ Stoffel ve ark., medial oblik açık kama osteotomisinde Puddu plağı ile plak fiksatörü karşılaştırmışlar. ${ }^{[11]}$ Lateral korteksin kırılmadığı hastalarda benzer biyomekanik sonuçlar elde edilmişken, lateral korteksin kırıldığı Puddu plağı uygulanan hastalarda lateral korteks için ek tespit ihtiyacı olduğu bildirilmiştir. ${ }^{[11]}$

PTMAKO şekline, yerleşimine ve planlarına göre farklı şekilde uygulanabilmektedir. Ekstremite düzlemlerine göre tek veya iki planlı uygulanabilir. Tek planlı osteotomiler, tibial tüberkülün altından veya üstünden, transvers ya da oblik planlarda uygulanabilir. ${ }^{[2,6]}$ iki planlı osteotomiler, patellar tendonun yapıştığı tibial tüberkülün proksimal ya da distal fragmanda bırakılmasına göre iki farklı şekilde yapılabilir (Şekil 2). ${ }^{[9,11,15]}$ Tüm osteotomi şekillerinde plak fiksatör tespit amaçlı uygulanabilmektedir.

\section{PTMAKO HASTA SEÇIMI}

PTMAKO'de amaç; stabil, dizilim bozukluğu giderilmiş, ağrısız ve hareket açıklığı korunmuş bir diz eklemi elde edilmesidir. Bu amaçlara ulaşmak için doğru hasta seçimi ve cerrahi teknik önem arz etmektedir. PTMAKO kesin endikasyonları; aktif, uyumlu, 65 yaş altı, $15^{\circ}$ 'den az varus deformitesi, $100^{\circ}$ 'den fazla hareket açıklığı, $10^{\circ}$ 'den az fleksiyon kontraktürü ve Ahlback evre 1-2 medial kompartman artrozu olan hastalar olarak belirtilebilir. Kesin kontrendikasyonları ise; diffüz, inflamatuvar artrit, ciddi vasküler yetmezlik, lateral menisektomi hikâyesi, tibiofemoral eklem subluksasyonu (1 santimetreden fazla) ve ileri patellafemoral eklem artrozu olan hastalardır. Göreceli kontraendikasyonlar arasında; 65 yaş üzeri, Vücut Kitle İndeksi (VKi) 30 kg/ $\mathrm{m}^{2}$ 'nin üzeri, bacak uzamasının istenmediği durumlar, patella baja (infera) ve sigara kullanımı sayılabilir. ${ }^{[16]}$ Ön çapraz bağ (ÖÇB) veya arka çapraz bağ (AÇB) yetmezliğin olduğu vakalarda PTMAKO'si ile sagittal planda posterior tibial eğim değiştirerek instabiliteyi tedavi etmek mümkündür. ${ }^{[6,15]}$ ÖÇB yetmezliğine bağlı instabilitesi olan vakalarda posterior tibial eğimi azaltmak, $A C ̧ B$ yetmezliği olan vakalarda ise posterior tibial eğimi artırmak şikâyetleri ortadan kaldırabilmektedir. Varus deformitesiyle beraber ÖÇB yetersizliği olan hastalarda bir diğer seçenek PTMAKO ile birlikte ÖÇB rekonstrüksiyonu da yapılmasıdır. ${ }^{[6,15]}$ PTMAKO uygulamalarından sonra, düzeltilen deformite derecesinin yarısı kadar tibial tüberkül aşağıya doğru yer değiştirdiği için patella infera durumunda tek planlı oblik osteotomi yapılması uygun değildir. ${ }^{[6]}$ Ancak tibial tüberkülün 

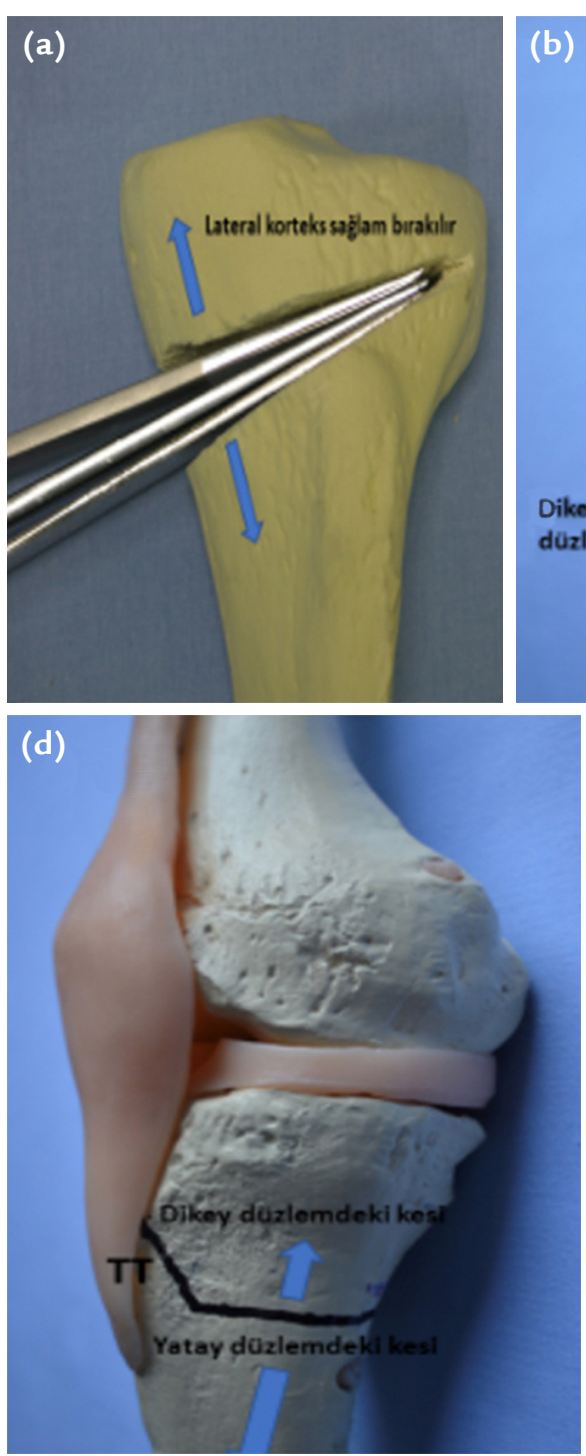
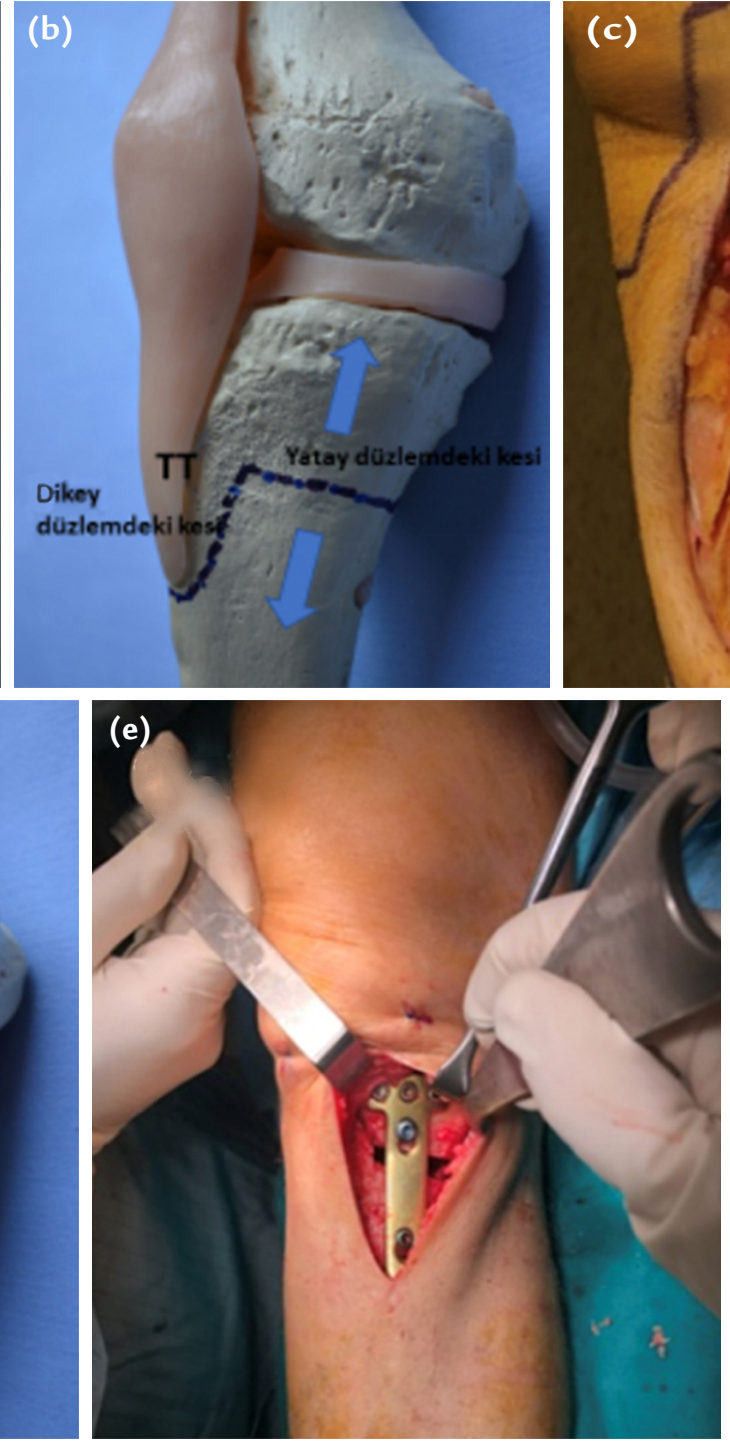

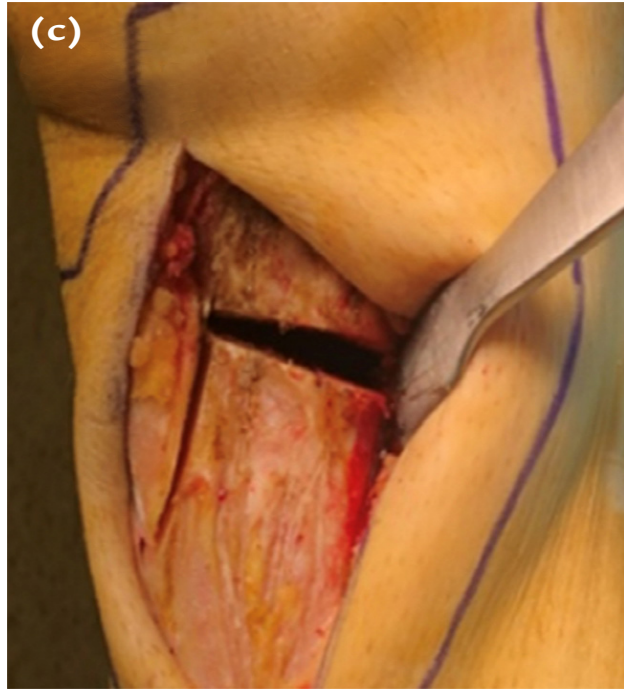

Şekil 2. a-e. Proksimal tibia medial oblik açık kama osteotomisinin görünümü (a). Proksimal tibia retrotuberkül osteotomisinin görünümü $(b, c)$. Proksimal tibia biplanar osteotomisinin görünümü (d, e). (a, b ve d, Prof. Dr. Irfan Esenkaya'nın arşivinden.) proksimal fragmanda bırakıldığı iki planlı retrotüberkül osteotomi tekniği ile bu sorunun üstesinden gelindiği bildirilmiştir. ${ }^{1]}$

\section{Preoperatif Değerlendirme}

Başarılı cerrahi için hastaların hem klinik hem de radyolojik açıdan detaylı değerlendirilmesi gereklidir. Diz eklemi hareket açıklığı, stabilitesi ve alt ekstremite dizilimi değerlendirilmelidir. Lateral kompartman ve patello-femoral eklem muayenesi dikkatli yapılmalıdır. ${ }^{[8]}$ Preoperatif radyolojik tetkikler arasında; basarak diz ön-arka grafisi, diz $30^{\circ}$ fleksiyonda lateral grafi, $45^{\circ}$ fleksiyonda patella tanjansiyel grafi, $45^{\circ}$ fleksiyonda arka-ön 'Rosenberg grafisi' ve her iki alt ekstremite uzunluk grafileri (ortoröntgenografi) çekilmelidir.

Standart ön-arka diz grafisinde medial-lateral kompartman ve dizilim, lateral grafide patello- femoral eklem, patella yüksekliği ve posterior tibial eğim değerlendirilir. Patella tanjansiyel grafi ile patello-femoral eklem ve patella yerleşimi incelenir. Ayakta çekilen alt ekstremite uzunluk grafisi (kalça-diz-ayak bileğini içeren) osteotomi belirleme ve planlamada kullanılmaktadır. Femur başı orta noktasından, ayak bileği eklem orta noktasına çekilen mekanik aks (eksen) çizgisinin diz eklemi ortasının $8 \pm 7 \mathrm{~mm}$ medialinden geçmesi normal olarak değerlendirilir. Ayrıca Medial Proksimal 

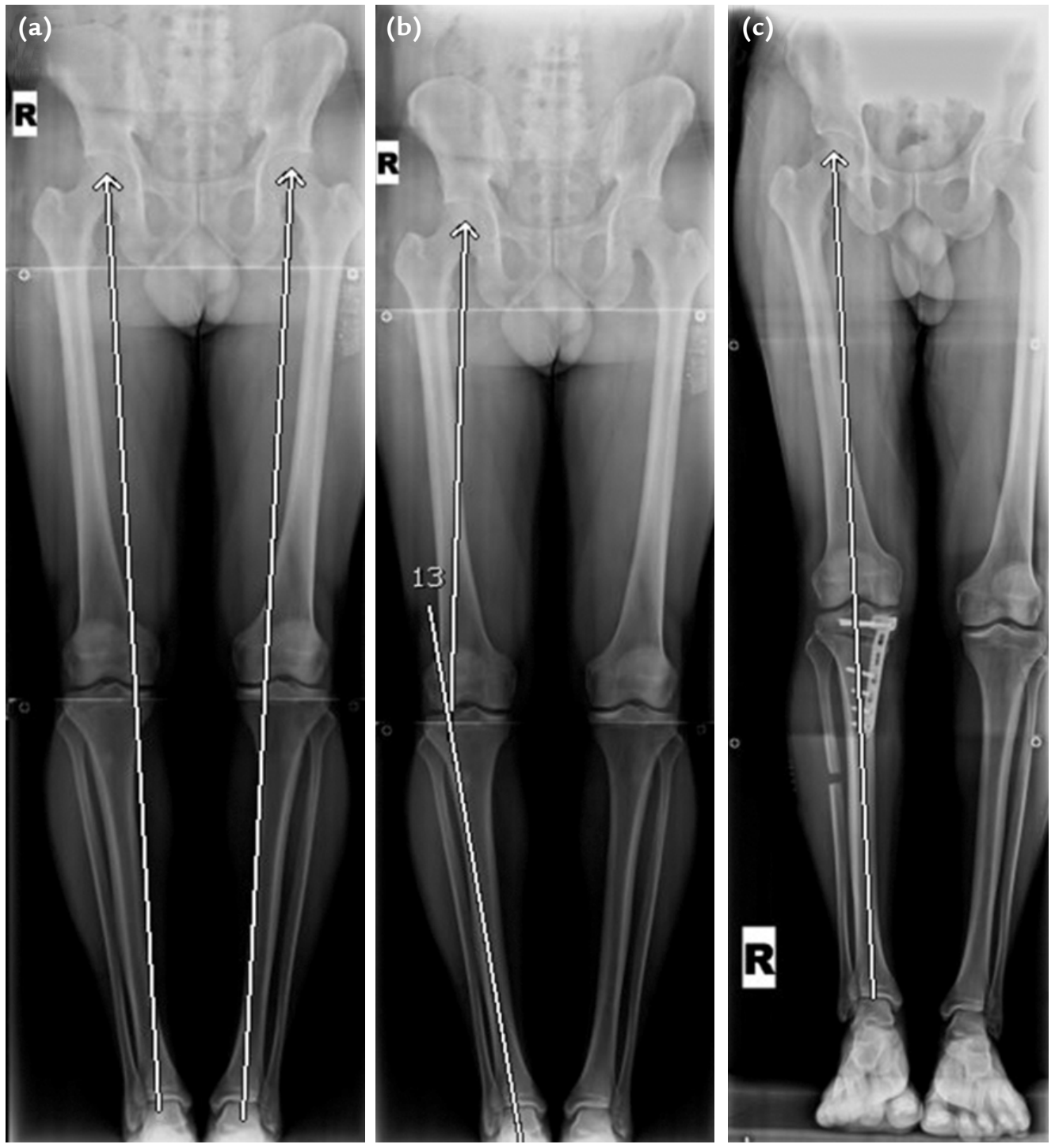

Şekil 3. a-c. Her iki alt ekstremite ortoröntgenografide sağ alt ekstremite mekanik aksın mediale yer değiştirmesi (a, beyaz çizgi). 'Fujisawa noktası'na göre alt akstremitede düzeltilmesi gereken açının hesaplanması (b, beyaz çizgiler). Proksimal tibia medial açık kama osteotomisi, fibula osteotomisi ve plak fiksatör sistemi ile yapılan fiksasyon sonrası düzeltilmiş alt ekstremite mekanik aksın ölçülmesi (c, beyaz ok).

Tibial Açı $\left(\mathrm{MPTA}=87^{\circ} \pm 3^{\circ}\right)$ ve Lateral Distal Femoral Açı $\left(\right.$ LTFA $\left.=87^{\circ} \pm 3^{\circ}\right)$ ölçümlerinin yapılması deformitenin kaynağı hakkında bilgi verecektir. Radyolojik değerlendirmede medial kompartman kıkırdak kaybını, lateral- patello-femoral eklem kıkırdak durumunu, menisküs ve bağ lezyonlarını değerlendirmede kullanılabilmektedir. ${ }^{[17]}$

\section{Cerrrahi Öncesi Planlama}

Amaç, koronal planda alt ekstremite mekanik eksenin 'Fujisawa noktası' olarak da adlandırılan, diz ekleminin \%62.5 lateralden geçecek şekilde düzeltilmesidir (Şekil 3). ${ }^{[2,18,19]}$ Düzeltme sonrası postoperatif $3-5^{\circ}$ valgus dizilimi sağlanır. Sagittal planda mekanik aksın diz orta noktasından geçmesi, posterior tibial eğimin korunması veya düzeltilmesi önemlidir. ${ }^{[17]} A C ̧ B$ yetmezliği olan vakalarda ise posterior tibial eğimi artırılmasını sağlayan medial oblik açık kama osteotomisi uygulanabilir. ÖÇB yetmezliğine bağlı instabilitesi olan hastalarda ise posterior tibial eğimin azaltılması osteotomi ile sağlanabilmektedir. ${ }^{[1]}$

\section{CERRAHI TEKNIK}

Cerrahi uygulanacak ameliyat masasının ışın geçirgen olması ve cerrahiye başlamadan önce kalça, diz ve ayak bileğinin skopi ile görülebilir olduğunun kontrol edilmesi gereklidir. Uyluk bölgesinde turnike sarılarak supin (sırtüstü) pozisyonda cerrahın tercihine bağı olarak 
diz fleksiyon veya ekstansiyon pozisyonunda hasta hazırlanır. Spinal veya genel anestezi sonrası aynı veya karşı tarafiliak kanattan greft alınacak şekilde boyama yapılmalıdır. Eklem içini değerlendirmek için artroskopik girişim ile başlanır. Artroskopik girişim ile eklem içi kondral, meniskal ve ön-arka çapraz bağ patolojilere yönelik değerlendirme ve müdahale yapilır. Ayrıca MAKO kontrendikasyonları arasında yer alan lateral kompartman kıkırdak sorunları araştırılır. Artroskopi sonrası osteotomi için diz ekstansiyona alınır.

Değişik yazarlar PTMAKO için farklı (transvers, oblik, uzunlamasına veya diz önünden içbükey eğimi mediale bakan) kesi uyguladıklarını bildirmişlerdir. ${ }^{[20,21]}$ ileride total diz protezi (TDP) uygulamak gerektiğinde, yapılacak orta hattan uzunlamasına kesi ile çakışmayacak insizyon planlanmalıdır. Diz eklemi ekstansiyonda iken, eklem seviyesinin altından başlayarak, patellar tendon mediali ile tibianın arka kenarı arasından ortalama 7-9 santimetre $(\mathrm{cm})$ uzunluğunda uzunlamasına cilt kesisi yapılır (Şekil 4a). Medial tibia üzerindeki periost, kısa bacağı arkaya bakan ters "L" şeklinde kesilir. Pes anserius subperistal olarak sıyrılır ve iç yan bağ lifleri posteromedial kortekse kadar gevşetilir. Tibia posteromedialine nörovasküler yapıları korumak için elevatörler konur. Ardından 2 adet 1,8-2 milimetre $(\mathrm{mm})$ 'lik Kirschner $(\mathrm{K})$ teli sagital ve koronal planda tibia eklem yüzeyine paralel olacak şekilde medialden laterale doğru gönderilir. Patella orta hatta olan pozisyonda diz eklemi medial tibia platosunun $3,5-4 \mathrm{~cm}$ distalinden skopi kontrolünde lateral-proksimale doğru fibula başı hedeflenerek iki veya üç adet 1,8-2 mm $K$ teli gönderilir (Şekil $4 b$ ). Bu aşamada tüberositas tibia ve patellar tendon yapışma yeri ortaya konur. Diz eklemi fleksiyona alınır. Tek planlı MAKO için K telleri distalinden, patellar tendon korunarak tuberistas tibia proksimalinden olacak şekilde medial korteks ince kesici motor ile kesilir. Ardından farklı boyutlardaki osteotomlar ile posterior ve anteromedial korteks, tibia lateral korteksine $1 \mathrm{~cm}$ kalacak şekilde kesilir. Eğer yatay ve distale dikey iki osteotomi hattı içeren retrotüberkül MAKO yapılacak ise yatay osteotomi uzunluğu tibia medial genişliğinin 2/3'ü (orta ve posterior) kadar olmalıdır. Ardından ön 1/3'lük osteotomi hattı, posterior osteotomi hattı ile $110-120^{\circ}$ açı yapacak şekilde, tibia uzun aksına paralel distale doğru en az $2,5 \mathrm{~cm}$ tüberistas tibia kemik blok olacak şekilde tamamlanır (Şekil 2. b, c). Yatay ve proksimale dikey iki osteotomi hattı içeren tüberositas tibia proksimalinden geçen iki planlı MAKO yapılacak ise medial tibia 2/3 posterior yatay osteotomi hattı ile $130^{\circ}$ açı yapacak şekilde retrotüberkül alandan proksimale doğru ön $1 / 3$ anterior korteks osteotomisi yapılır (Şekil 2. d, e). Daha sonra açı göstergeli distraktör veya iki osteotom arasından üçüncü bir osteotom yollanarak osteotomi hattı skopi kontrolünde açılır (Şekil 4. c, d). Bu sırada proksimal ve distal $\mathrm{K}$ tellerinin paralel olması da posterior tibial eğimde değişme olmadığının bir göstergesi olabilir. Genel olarak posterior tibial eğimin değişmemesi için posterior korteksdeki açılma miktarı anteriorun 1,5-2 katı olmalıdır. Posterior tibial eğim bu aşamada çapraz bağ yetmezliğine bağlı instabilitesi olan vakalarda değiştirilebilir. Ekstremite mekanik aks değerlendirilmesi için kablo testi koter kablosu ile yapılabilir. Osteotomi hattı hesaplanan miktar kadar açıldıktan sonra, patella tam anterior orta hatta olduğu pozisyonda alt ekstremite ekstansiyona alınır. Skopi yardımıyla koter kablosu femur başı merkezi ve ayak bileği eklemi orta noktası arasında sabitlenir ve gerilir. Mekanik aksı gösteren kablonun, skopi ile diz ekleminde istenen noktadan geçtiği görüldüğü takdirde osteotomi hattı; laminar ayırıcı ve plak konmasını engellemeyen distraktör ile sabitlenir. Ardından Tomofix (plak fiksatör) tibia proksimal medialine yerleştirilir (Şekil 4. e, f). Skopi ile kontrol edilir. Proksimal kilitli kortikal üç adet vida yerleştirilir. Plak distalindeki vidalar, cilt altında kolayca palpe edilebilen vida delikleri üzerinden vida geçebilecek kadar küçük insizyonlar yapılarak yerleştirilir. En son olarak proksimaldeki spongioz kilitsiz vida yollanabilir (Şekil 4g). Fiksasyon yapıldıktan sonra osteotomi açılması $12-14^{\circ}$ 'yi aşıyorsa iliak kanattan alınan mono ya da trikortikal otogreft, sentetik greftler veya allogreftler defektli bölgeye konulabilir. ${ }^{[7,17,21]}$ Yara yerinin kapatılması öncesi turnike açılarak kanama kontrolü yapılır ve sonrasında kaz ayağının (pes anserinusun) uzun kolu plak üzerine dikilir. Hemovak dren pasif konumda uygulanabilir. Cerrahi kapama sonrası ayak parmaklardan başlanarak uyluk ortasına kadar elastik bandaj uygulanır.

Ameliyat sonrası (postoperatif) birinci günde aktifve pasif diz eklem hareket açıklığı ve terminal ekstansiyon egzersizleri başlanır. Çift kanedyen baston veya koltuk değneği ile parsiyel yük vererek yürüme egzersizleri öğretilir. Altıncı haftada grafi kontrol sonrası tam yük ile yürümeye izin verilir.

\section{KLINIK SONUÇLAR}

Medial açık kama osteotomisinin kısa ve uzun dönem klinik sonuçlarını değerlendiren çalışmalar mevcuttur. ${ }^{[22,23]}$ Lobenhoffer ve ark. biplanar PTMAKO'si hastalarında plak fiksatör ile yapılan fiksasyonun sonucunda tüm hastalarda fonksiyonel iyileşme ve kaynama tespit edildiği belirtilmiştir. ${ }^{[10]}$ Jung ve ark. önarka dikey kamalı plakları (dikey kamalı blok sistem, Aescula Aesculap; B. Braun Korea, Seoul, South Korea) ile plak fiksötörü karşılaştırdıkları çalışmalarında, her iki plakta fonksiyonel diz skorlarında anlamlı iyileşme bulunmuştur. Ancak dikey kamalı plaklarda 

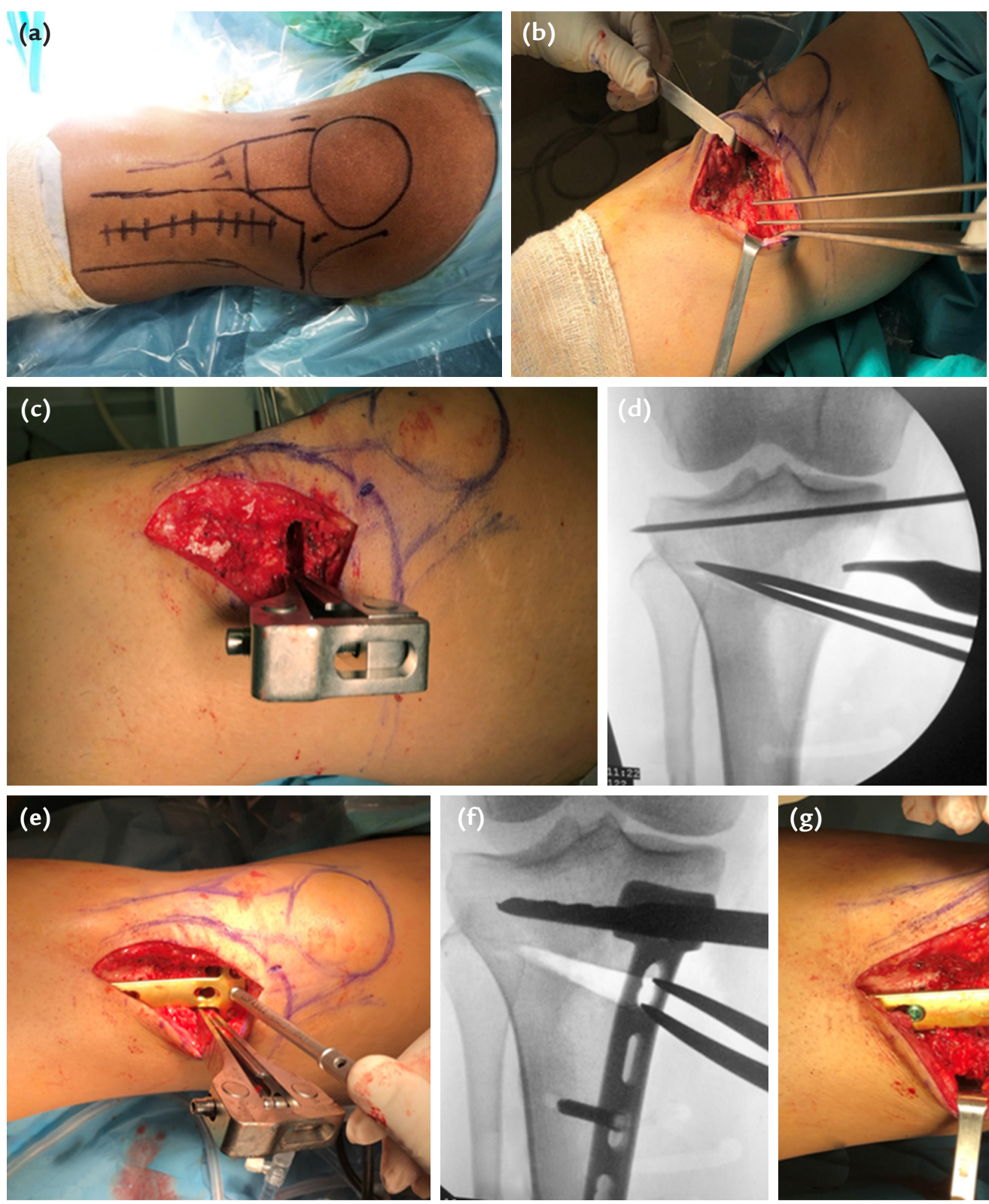

Şekil 4. a-g. Diz anatomisi göstergeçlerin ve proksimal tibia medial insizyon çizimi (a). Osteotomi hattı belirlemek için medialden laterale yollanan $\mathrm{K}$ tellerinin görünümü (b). Osteotomi hattının açı ayarlı distraktör ile açılması ve skopi görünümü $(c, d)$. Açılan osteotomi sahasına plak fiksatör yerleştirilmesi ve vidaların gönderilmesi (e, f). Plak fiksatör sistemin osteotomi alanına fiksasyonun son hali ( $(\mathrm{g})$. komplikasyon oranı \%38 iken, plak fiksatörde ise \%28 olarak tespit etmişlerdir. ${ }^{[4]}$ Tek planlı PTMAKO'sinde kullanılan kamalı plak sistemlerine alternatif olarak geliştirilen 'metal blok eklemeli' kilitli plakların plak fiksatör'e göre komplikasyon oranları daha yüksek bulunmuştur. Çok planlı kilitli tasarımlarla, plak fiksatörü karşılaştıran klinik çalışmada her iki grupta da anlamlı klinik iyileşme görülmüştür. ${ }^{[24]}$ Kyung ve ark., biplanar PTMAKO hastalarında kamalı plak uygulanan gruba göre, plak fiksatör grubunda kaynama zamanını daha kısa ve komplikasyon oranını da daha düşük olarak bulunmuştur. ${ }^{[24]}$ Plak fiksatör ile retrotuberkul PTMAKO yapılan hastaların ortalama iki yıllık takiplerinde hastaların klinik skorlarında anlamlı düzelme sağlanması ile birlikte erken hareket ve breys kullanım ihtiyacı olmadığı bildirilmiştir. [25] Hantes ve ark., aktif 45 yaş altı hastalarda plak fiksatör ile fiksasyon yapılan PTMAKO vakalarında 12 yıllık sağ kalım sonucunun \%95 olduğunu belirtmişlerdir. ${ }^{[26]}$ Plak fiksatör kullanılarak PTMAKO yapılan geniş vaka serisinde 2-5 yıllık takiplerde anlamlı fonksiyonel iyileşme elde edilmiştir. Ancak ileri evre osteoartrit ve yüksek hasta yaşının klinik sonuçları olumsuz etkilediği bulunmuştur. ${ }^{[27]}$ 


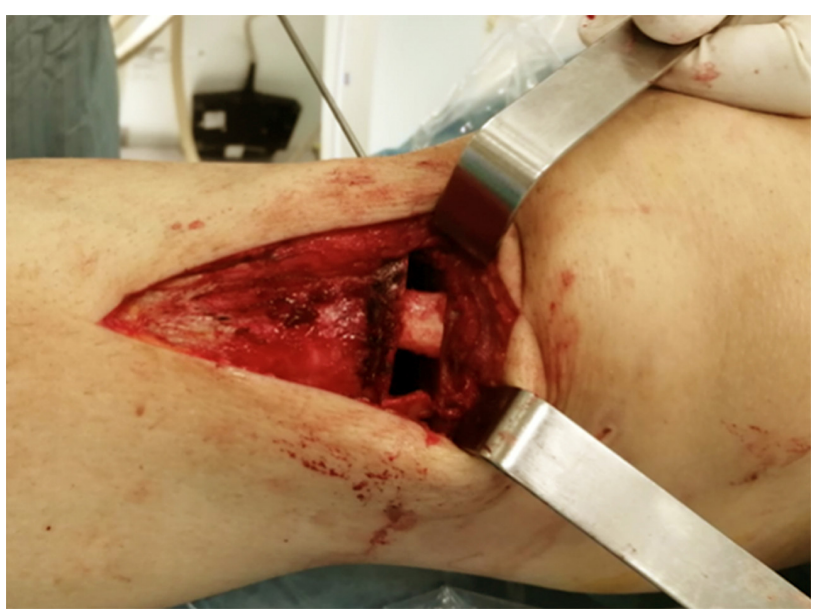

Şekil 5. Osteotomi hattına yerleştirilmiş fibula otogrefti görünümü.

\section{Kemik Grefti Uygulaması}

Medial açık kama osteotomi hattının greftlenmesi konusunda tartışmalar devam etmektedir. Greft kullanılmadan yapılan tespitlerde \%40'a varan mekanik komplikasyon görülebilir. ${ }^{[28]}$ Kamalı plaklarda 7 mm'den fazla düzeltme gerektiren olgularda greft kullanılması önerilmiş iken, yeni nesil uzun kilitli plak vida sistemlerinin kullanıldığı olgularda 14 mm'ye kadar olan düzeltmelerde greftlemeye gerek olmayabileceği bildirilmiş̧tir. ${ }^{[29]}$ Fakat aşırı kilolu, sigara kullanan ve $10 \mathrm{~mm}$ 'den daha fazla düzeltme yapılan vakalarda greftleme gerekebileceği bildirilmiştir. On yıllık klinik takip sonucunda plak fiksatör kullanılan ortalama $9^{\circ}$ düzeltme yapılan PTMAKO hastalarında greft kullanmamanın sonuçları etkilemediği ve düzeltme kaybına neden olmadığı bildirilmişsir. ${ }^{[30]}$

Greft seçenekleri arasında; iliak kanat kortikospongiz otogreftler, allogreftler, kemik çimentosu, hidroksiapatit veya kalsiyum fosfat yapıda olan sentetik greftler de bulunmaktadır.

Hernigou ve ark. distraksiyon sonrası oluşan boşluğun, iliak kristadan alınan kortikospongioz yapıdaki greft ile doldurulmasını önermiştir. ${ }^{[31]}$ Bazı yazarlar $7,5 \mathrm{~mm}$ ve altındaki distraksiyonlarda, Lobenhoffer ve ark. ise $15 \mathrm{~mm}$ kadar açtıkları osteotomilerde greft kullanmanın gerekli olmadığını bildirmektedirler. ${ }^{[6,15]}$ Otogreft kullanılması; alındığı bölgede ameliyat sonrası ağrıya, hematom oluşumuna, sepsise ve kıyafet giyerken rahatsızlığa neden olabilir. ${ }^{[31]}$ Hernigou ve ark., bu komplikasyonları önlemek için akrilik kemik çimentosu, Koshino ve ark. ise hidroksiapatit dolgu maddesi ve fibuladan (Şekil 5) çıkarılan kortikal kemiğin kullanımı ile iyi sonuçlar bildirmişlerdir. ${ }^{[31,32]}$ Son vakalarımızda YTO ile birlikte rutin fibula osteotomisi yapmaktayız, çıkardığımız fibula greftinide oluşan boşluğa göre keserek osteotomi alanına uygulamaktayız. $10^{\circ}$ 'den daha fazla düzeltme gerektiren veya lateral korteksi kırık olan vakalarda allogreft kullanımının, sonuçları olumlu etkilediği vurgulanmıştır. ${ }^{[33]}$

\section{Komplikasyonlar}

PTMAKO' ya bağlı komplikasyon oranı \%7-55 arasında değişmektedir. ${ }^{[4,28,34]}$ Komplikasyonlar arasında en sık ağrının devam etmesi, elde edilen düzeltmenin kaybı, lateral korteks kırılması, bacak boyunda uzama, lateral plato kırı̆ı, kaynamama, kaynama gecikmesi, implant irritasyonu, implant yetmezliği ve eklem sertliği sayılabilir.

PTMAKO hastalarında plak ile yapılan fiksasyon sonrası kaynamama oranı \%4,6 olarak bildirilmiştir. ${ }^{[34]}$ Plak fiksatör kullanılan vakalarda kaynamama oranı, Puddu plağına göre anlamlı daha düşük (sırasıyla \%3,6-8,3) bulunmuştur. Niemeyer ark.'nın üç yıllık takiplerinde plak fiksatöre bağlı implant irritasyon oranı $\% 40$, komplikasyon oranı ise \%8,6 olarak tespit edilmiştir. ${ }^{[23]}$ Geriye dönük bir çalışmada plak fiksatör ile diğer plaklar arasında implant çıkarma gerekliliği arasında fark bulunmamıştı. ${ }^{[34]}$ PTMAKO sonrası enfeksiyon oranı ortalama \%3,6 olarak bulunmuştur. ${ }^{[34]}$ Floerkemeier ve ark.'nın geriye dönük ortalama 3,6 yıl takipli plak fiksatör sistemi ile PTMAKO'si uygulanan 533 vakalık serilerinde ortalama komplikasyon oranı \%6 olarak bulunmuştur. En sık komplikasyonlar \%2,1 oranında yara yeri sorunları, \%1,5 oranında da kaynamama olarak bulunmuştur. ${ }^{[27]}$

\section{SONUÇ}

Varus dizilim bozukluğu ile seyreden medial kompartman osteoartritinin cerrahi tedavisinde medial açık kama osteotomisi yaygın olarak kullanılmaktadır. Medial açık kama osteotomisi tespitinde uygulanan plak fiksatör sistemlerinin klinik ve radyolojik sonuçları oldukça yüz güldürücüdür. Düşük komplikasyon oranları, erken hareket ve yük verme avantajlarından dolayı medial açık kama osteotomisinde plak fiksatör sistemleri güvenle uygulanabilir.

\section{KAYNAKLAR}

1. Elmalı N, Esenkaya I, Can M, Karakaplan M. Monoplanar versus biplanar medial open-wedge proximal tibial osteotomy for varus gonarthrosis: a comparison of clinical and radiological outcomes. Knee Surg Sports Traumatol Arthrosc 2013;21(12):2689-95. Crossref

2. Hernigou P, Medevielle D, Debeyre J, Goutallier D. Proximal tibial osteotomy for osteoarthritis with varus deformity: A ten to thirteenyear follow-up study. J Bone Joint Surg Am 1987;69(3):332-354. https://insights.ovid.com/pubmed?pmid=3818700

3. Agneskirchner JD, Freiling D, Hurschler C, Lobenhoffer P. Primary stability of four different implants for opening wedge high tibial osteotomy. Knee Surg Sports Traumatol Arthrosc 2006;14(3):291-300. Crossref 
4. Jung $\mathrm{WH}$, Chun $\mathrm{CW}$, Lee $\mathrm{JH}, \mathrm{Ha} J \mathrm{H}$, Kim JH, Jeong $\mathrm{JH}$. Comparative study of medial opening-wedge high tibial osteotomy using 2 different implants. Arthroscopy 2013;29(6):1063-71. Crossref

5. Goutallier D, Julieron A, Hernigou PH. La cale de ciment remplaçant les greffons iliaques dans les ostéotomies tibiales d'addition interne. Rev Chir Orthop Reparatrice Appar Mot 1992;78:138-44.

6. Franco V, Cerullo G, Cipolla M, Gianni E, Puddu G. Open wedge high tibial osteotomy. Tech Knee Surg 2002;1(1):4353. Crossref

7. Esenkaya I, Elmali N. Proximal tibia medial open-wedge osteotomy using plates with wedges: early results in 58 cases. Knee Surg Sports Traumatol Arthrosc 2006;14(10):955-61. Crossref

8. Kocadal O, M, Pepe IM, Aktekin CN. Medial Açık Kama Osteotomisi, Tek Planda - Kamalı Plaklarla. İçinde: Esenkaya I, Özenci M, Kocabey Y, Bombacı H, Köse Ö, editörler Diz Çevresi Osteomileri. TUSYAD Eğitici Kitap Serisi. İstanbul: İstanbul Tıp Kitabevi; 2018. ss.99-103.

9. Staubli AE, De Simoni C, Babst R, Lobenhoffer P. TomoFix: a new LCP-concept for open wedge osteotomy of the medial proximal tibia--early results in 92 cases. Injury 2003;34 Suppl 2:55-62. Crossref

10. Lobenhoffer P, Agneskirchner JD. Improvements in surgical technique of valgus high tibial osteotomy. Knee Surg Sports Traumatol Arthrosc 2003;11(3):132-8. Crossref

11. Stoffel K, Stachowiak G, Kuster M. Open wedge high tibial osteotomy: biomechanical investigation of the modified Arthrex Osteotomy Plate (Puddu Plate) and the TomoFix Plate. Clin Biomech (Bristol, Avon) 2004;19(9):944-50. Crossref

12. Kim KJ, Song EK, Seon JK, Seol JH. Biomechanical Study of the Fixation Plates For Opening Wedge High Tibial Osteotomy. Knee Surg Relat Res 2015;27(3):181-6. Crossref

13. Han SB, Bae JH, Lee SJ, Jung TG, Kim KH, Kwon JH, Nha $\mathrm{KW}$. Biomechanical properties of a new anatomical locking metal block plate for opening wedge high tibial osteotomy: uniplane osteotomy. Knee Surg Relat Res 2014;26(3):15561. Crossref

14. Takeuchi R, Woon-Hwa J, Ishikawa H, Yamaguchi $Y$, Osawa K, Akamatsu Y, Kuroda K. Primary stability of different plate positions and the role of bone substitute in open wedge high tibial osteotomy. Knee 2017;24(6):1299-306. Crossref

15. Lobenhoffer P, De Simoni C, Staubli AE. Open-wedge high tibial osteotomy with rigid plate fixation. Tech Knee Surg 2002;1(2):93-105. Crossref

16. Erduran M, Gürsan O, Tatari H. Diz çevresi osteotomilerde endikasyonlar ve kontrendikasyonlar. Içinde: Esenkaya i, Özenci M, Kocabey Y, Bombacı H, Köse Ö, editörler. Diz Çevresi Osteomileri. TUSYAD Eğitici Kitap Serisi. İstanbul: İstanbul Tıp Kitabevi; 2018. ss.23-7.

17. Tuncay I, Uzer G. Medial Açık Kama Osteotomisi, Tek Planda Tomofiks Plağı ile. Esenkaya I, Özenci M, Kocabey Y, Bombacı H, Köse Ö, editörler. TUSYAD Eğitici Kitap Serisi. İstanbul: İstanbul Tıp Kitabevi; 2018. ss.105-14.

18. Dugdale TW, Noyes FR, Styer D. Preoperative planning for high tibial osteotomy. The effect of lateral tibiofemoral separation and tibiofemoral length. Clin Orthop Relat Res 1992;(274):248-64. Crossref

19. Fujisawa $\mathrm{Y}$, Masuhara $\mathrm{K}$, Shiomi S. The effect of high tibial osteotomy on osteoarthritis of the knee. An arthroscopic study of 54 knee joints. Orthop Clin North Am 1979;10(3):585-608.

20. Hernigou Ph. Open wedge tibial osteotomy: combined coronal and sagittal correction. Knee 2002;9(1):15-20. Crossref
21. Esenkaya I. Fixation of proximal tibia medial opening wedge osteotomy using plates with wedge (Proksimal tibia medial açık kama osteotomisinde kamalı plak uygulaması). Acta Orthop Trauma Turc 2005;39(3):211-23. http://www.aott. org.tr/en/fixation-of-proximal-tibia-medial-opening-wedgeosteotomy-using-plates-with-wedges-164753

22. Schallberger A, Jacobi M, Wahl P, Maestretti G, Jakob RP. High tibial valgus osteotomy in unicompartmental medial osteoarthritis of the knee: a retrospective follow-up study over 13-21 years. Knee Surg Sports Traumatol Arthrosc 2011;19(1):122-7. Crossref

23. Niemeyer $P$, Schmal H, Hauschild $O$, von Heyden J, Südkamp NP, Köstler W. Open-wedge osteotomy using an internal plate fixator in patients with medial-compartment gonarthritis and varus malalignment: 3 -year results with regard to preoperative arthroscopic and radiographic findings. Arthroscopy 2010;26(12):1607-16. Crossref

24. Kyung HS, Lee BJ, Kim JW, Yoon SD. Biplanar Open Wedge High Tibial Osteotomy in the Medial Compartment Osteoarthritis of the Knee Joint: Comparison between the Aescula and TomoFix Plate. Clin Orthop Surg 2015;7(2):185-90. Crossref

25. Hopwood S, Khan W, Agarwal S. The biplanar open wedge high tibial osteotomy preserving the tibial tubercle. J Orthop Sci 2016;21(6):786-90. Crossref

26. Hantes ME, Natsaridis $P$, Koutalos AA, Ono $Y$, Doxariotis $\mathrm{N}$, Malizos KN. Satisfactory functional and radiological outcomes can be expected in young patients under 45 years old after open wedge high tibial osteotomy in a longterm follow-up. Knee Surg Sports Traumatol Arthrosc 2018;26(11):3199-205. Crossref

27. Floerkemeier S, Staubli AE, Schroeter S, Goldhahn S, Lobenhoffer P. Outcome after high tibial open-wedge osteotomy: a retrospective evaluation of 533 patients. Knee Surg Sports Traumatol Arthrosc 2013;21(1):170-80. Crossref

28. Schröter S, Gonser CE, Konstantinidis L, Helwig P, Albrecht D. High complication rate after biplanar open wedge high tibial osteotomy stabilized with a new spacer plate (Position HTO plate) without bone substitute. Arthroscopy 2011;27(5):644-52. Crossref

29. El-Assal MA, Khalifa YE, Abdel-Hamid MM, Said HG, Bakr HM. Opening-wedge high tibial osteotomy without bone graft. Knee Surg Sports Traumatol Arthrosc 2010;18(7):9616. Crossref

30. Darees M, Putman S, Brosset T, Roumazeille T, Pasquier G, Migaud $\mathrm{H}$ Opening-wedge high tibial osteotomy performed with locking plate fixation (TomoFix) and early weightbearing but without filling the defect. A concise follow-up note of 48 cases at 10 years' follow-up. Orthop Traumatol Surg Res 2018;104(4):477-80. Crossref

31. Hernigou P, Ma W. Open wedge tibial osteotomy with acrylic bone cement as bone substitute. Knee 2001;8(2):103-10,. Crossref

32. Koshino T, Murase T, Saito T. Medial opening-wedge high tibial osteotomy with use of porous hydroxyapatite to treat medial compartment osteoarthritis of the knee. J Bone Joint Surg Am 2003;85(1):78-85. Crossref

33. Belsey J, Diffo Kaze A, Jobson S, Faulkner J, Maas S, Khakha $\mathrm{R}$, Pape D, Wilson AJ. The biomechanical effects of allograft wedges used for large corrections during medial openingwedge high tibial osteotomy. PLoS One 2019;14(5):e0216660. Crossref

34. Woodacre T, Ricketts M, Evans JT, Pavlou G, Schranz P, Hockings M, Toms A. Complications associated with opening wedge high tibial osteotomy --A review of the literature and of 15 years of experience. Knee 2016;23(2):276-82. Crossref 